\title{
Kehr tube complication: recurrent hepatic abscess associated with actinomyces secondary to a foreign body in the bile duct-a case report
}

\author{
Héctor F. Losada ${ }^{1,2,3}$, Andrés I. Troncoso ${ }^{1,2,3}$, Hernán A. Herrera ${ }^{1,2,3}$, Jorge A. Silva ${ }^{1,2,3}$, Juan A. Alvarado ${ }^{1}$, \\ Pablo I. San Martín ${ }^{1}$, Renato E. Becker ${ }^{4}$ \\ ${ }^{1}$ Team of Hepato-Bilio-Pancreatic Surgery, Department of Surgery, Traumatology and Anesthesiology, University of the Frontera, Temuco, Chile; \\ ${ }^{2}$ Team of Hepato-Bilio-Pancreatic Surgery, Hernán Henríquez Aravena Hospital, Temuco, Chile; ${ }^{3}$ Team of Hepato-Bilio-Pancreatic Surgery, \\ Alemana Temuco Clinic, Temuco, Chile; ${ }^{4}$ Department of Anatomy Pathology, University of the Frontera, Temuco, Chile \\ Correspondence to: Héctor F. Losada. Team of Hepato-Bilio-Pancreatic Surgery, Department of Surgery, Traumatology and Anesthesiology, University \\ of the Frontera, Manuel Montt 112, Temuco, Chile. Email: hector.losada@ufrontera.cl.
}

\begin{abstract}
Complications from the installation of a Kehr tube are frequent, up to $15 \%$ in some series. Hepatic abscesses secondary to a foreign intraciliary body are very rare. Actinomycosis is a rare chronic infection, has a liver involvement of $5 \%$ secondary to another intra-abdominal infection. We present a case of female patient aged 79 years. History of choledochostomy in 2007 due to choledocholithiasis and endoscopic biliary drainage due to residual choledocholithiasis. She consulted for pain in the epigastrium and right hypochondrium, associated with an increase in inflammation markers. Initial ultrasound identified a lesion in the left hepatic lobe compatible with a hepatic abscess. Nuclear magnetic resonance (NMR) revealed dilation of the intrahepatic bile duct, greater to the left, with thickening of the bile duct at the confluence level that extends to the middle third, with hepatolithiasis and choledocholithiasis and multiple hepatic abscesses. A left lateral segmentectomy was performed along with exploration of the bile duct, identifying a foreign body compatible with an old fragment of $T$ tube. The deferred biopsy reported intrahepatic lithiasis and chronic hepatitis compatible with secondary biliary cirrhosis, acute and chronic hepatitis with purulent leukocytic exudate and actinomycete elements. In our case the $T$ tube fragment could have acted as a foreign body and facilitated the infection by actinomyces.
\end{abstract}

Keywords: Liver abscess; biliary tract diseases; actinomyces; case report; surgery

Received: 28 October 2019; Accepted: 20 May 2021; Published: 30 September 2021.

doi: $10.21037 /$ asj-19-3

View this article at: https://dx.doi.org/10.21037/asj-19-3

\section{Introduction}

Complications due to the installation of a Kehr tube are frequent, up to $15 \%$ in some series, and include hydroelectrolytic disorders, sepsis, displacement, external biliary fistula, biloma and biliary peritonitis (1).

Hepatic abscesses secondary to a foreign intrabiliary body, on the other hand, are very rare (2). There are no reports in the literature of clinical cases on abscesses secondary to $\mathrm{T}$ tube fragments; therefore, we present the case of a patient with previous choledochostomy who consulted for recurrent hepatic abscesses associated with the presence of a $\mathrm{T}$ tube fragment as a foreign body in the bile duct.

Actinomycosis is a rare chronic, granulomatous infection caused by gram-positive bacilli of Actinomyces. There are a number of different species, but only a few are associated with human disease. The most common pathogenic specie in humans is Actinomyces israelii (3). These bacteria are the most abundant among the commensal flora of the oropharynx, the gastrointestinal tract, and the female genital tract (4). Its presence is more frequently associated with cervicofacial infection. Liver involvement represents $5 \%$ of all cases of actinomycosis, and is usually secondary 


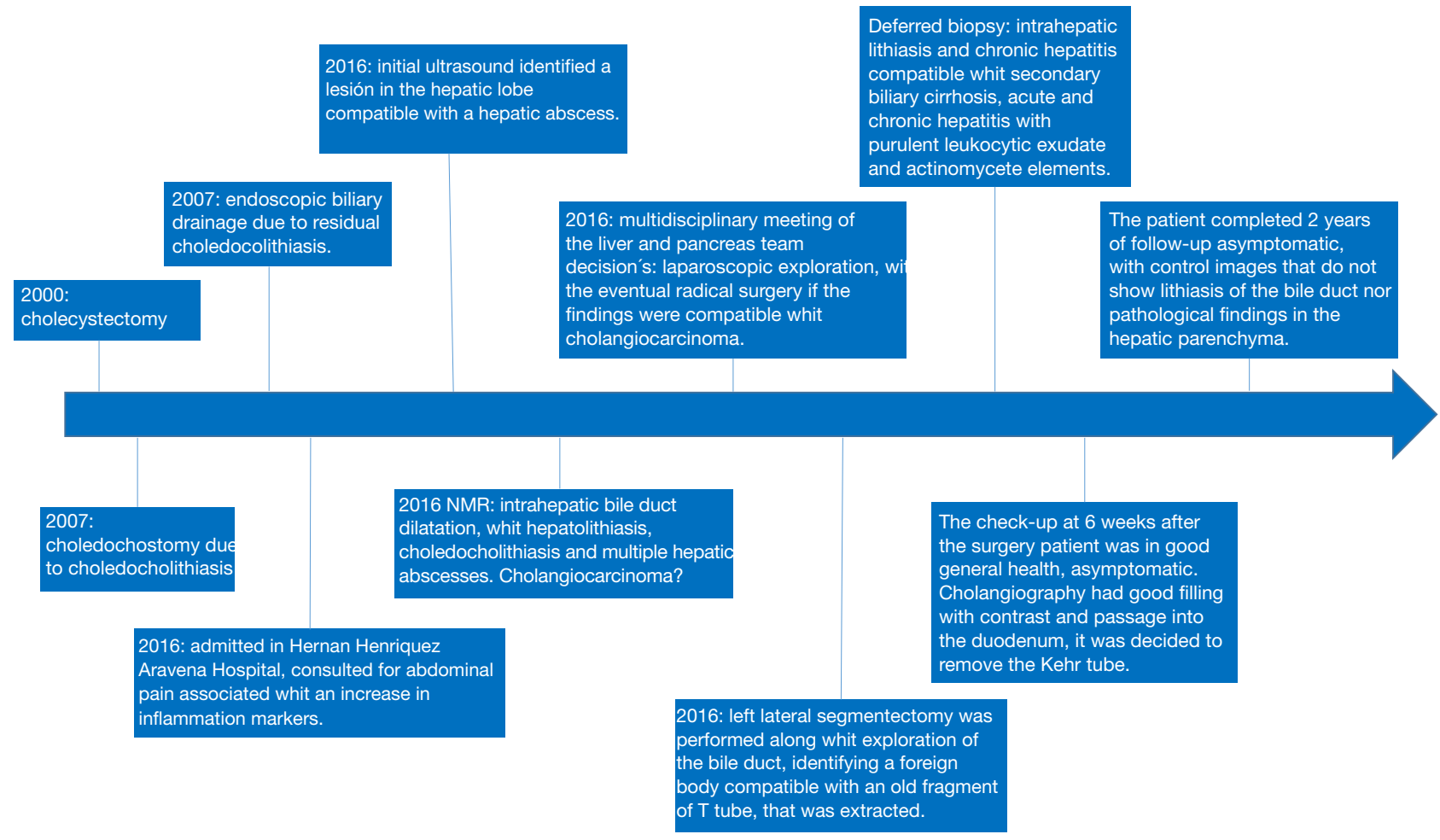

Figure 1 Clinical case timeline. NMR, nuclear magnetic resonance.

to another intraabdominal infection. The insidious course with nonspecific symptoms makes the diagnosis of this condition a challenging (5). We present the following article in accordance with the CARE reporting checklist (available at https://asj.amegroups.com/article/view/10.21037/asj-19$3 / \mathrm{rc})$.

\section{Case presentation}

Female patient aged 79 years. History of cholecystectomy in 2000, choledochostomy in 2007 for choledocholithiasis and during the same year, 2 months later, endoscopic biliary drainage was performed for residual choledocholithiasis, no other filling defects were observed during the procedure (Figure 1).

In 2016, she was admitted to the Hospital Hernán Henríquez Aravena in Temuco due to pain in the epigastrium and right hypochondrium, associated with an increase in inflammation markers and obstructive pattern in liver function test. Tumoral markers did not show significant elevation. Physical examination revealed pain on palpation of the right upper quadrant and epigastrium associated with a palpable indurated mass in the right hypochondrium. Initial ultrasound identified a lesion in the left hepatic lobe compatible with a hepatic abscess. Nuclear magnetic resonance (NMR) was performed on the liver, which revealed dilatation of the intrahepatic bile duct which was greater on the left, with thickening of the bile duct at the level of the confluence that extends to the middle third of the bile duct, with hepatolithiasis, choledocholithiasis and multiple hepatic abscesses. The possibility of a cholangiocarcinoma was considered given the image of thickening of the bile duct at the confluence (Figures 2,3).

The patient was discussed in the multidisciplinary meeting of the liver and pancreas team, and the decision was made to perform a laparoscopic surgical exploration, with a plan for radical surgery in the event that the findings were compatible with cholangiocarcinoma. The images showed greater involvement on the left, with atrophy of the left lateral segment and saccular dilatations of the left intrahepatic bile duct, with intrahepatic lithiasis, findings compatible with Caroli disease.

No hepatic metastases or adenopathies were found during the laparotomy; however, atrophy was encountered in the left lateral segment, with multiple hepatic abscesses and cystical dilatation, thickening of the bile duct, with no evidence on palpation of a clear tumor area. A left lateral 


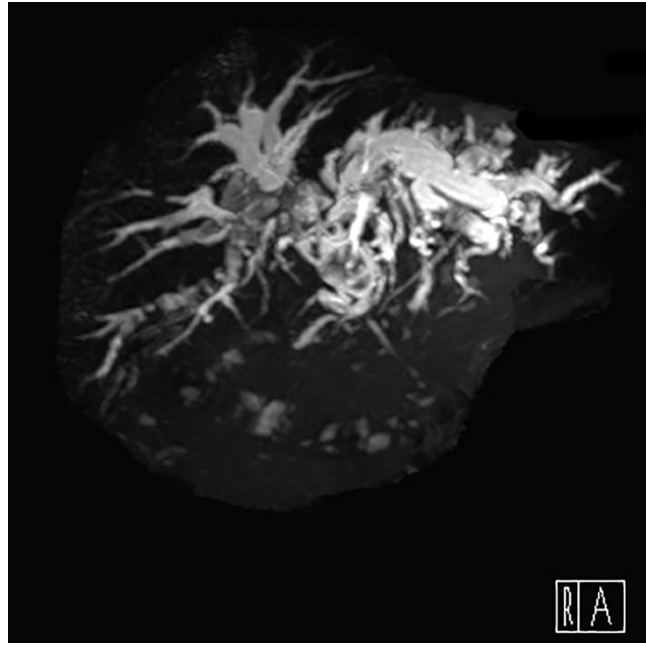

Figure 2 Dilated intrahepatic bile duct with greater involvement on the left.

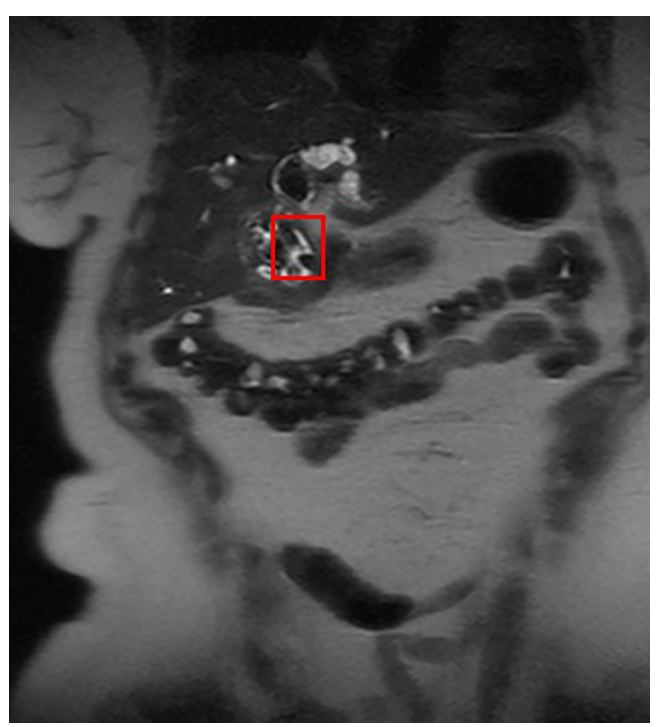

Figure 3 Saccular dilatation of the bile duct with stones in hepatic left duct. Image compatible with $\mathrm{T}$ tube segment (linear defect in box). Analysis after intraoperative findings, initially confused with lithiasis.

segmentectomy was performed along with exploration of the bile duct, identifying a foreign body compatible with an old fragment of $\mathrm{T}$ tube. The foreign body was extracted (Figure 4) and a choledochostomy was installed with a $\mathrm{T}$ probe, once a cholangiography had been performed that showed no alterations.

The patient evolved with no postoperative complications

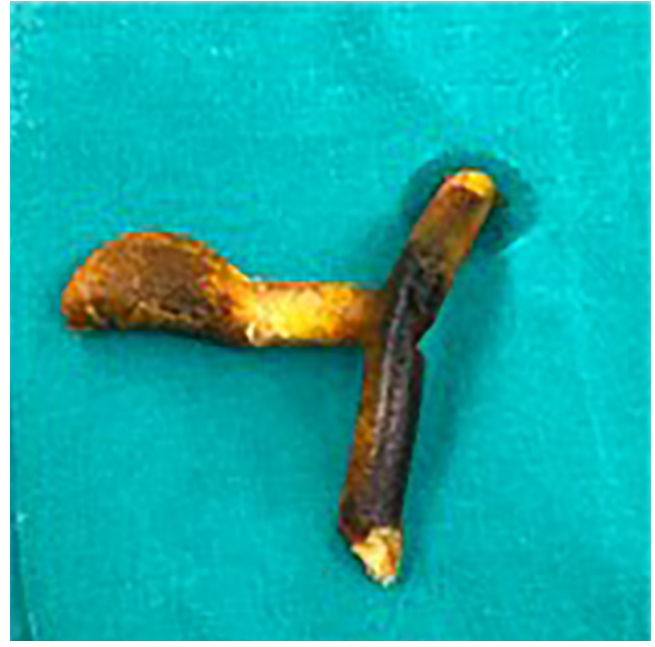

Figure 4 Foreign body compatible whit $\mathrm{T}$ tube fragment.

and was discharged on the fifth day.

The deferred biopsy reported intrahepatic lithiasis and chronic hepatitis compatible with secondary biliary cirrhosis, acute and chronic hepatitis with purulent leukocytic exudate and actinomycete elements (Figure 5A,B and Figure 6A,B).

The check-up at 6 weeks after the surgery included a new cholangiography by T-tube. Given that she was in good general health, asymptomatic and the cholangiography had good filling with contrast and passage into the duodenum, it was decided to remove the Kehr tube.

The patient completed 2 years of follow-up, asymptomatic, with control images that do not show lithiasis of the bile duct nor pathological findings in the hepatic parenchyma.

All procedures performed in this study were in accordance with the ethical standards of the institutional and/or national research committee(s) and with the Helsinki Declaration (as revised in 2013). Written informed consent was obtained from the patient for publication of this case report and accompanying images. A copy of the written consent is available for review by the editorial office of this journal.

\section{Discussion}

Hepatic abscesses due to foreign bodies are rare, even more so secondary to a Kehr tube fragment. No other similar cases were found in the literature.

Actinomycosis is a rare, chronic infection caused by gram-positive filamentous bacilli of the genus Actinomyces. 

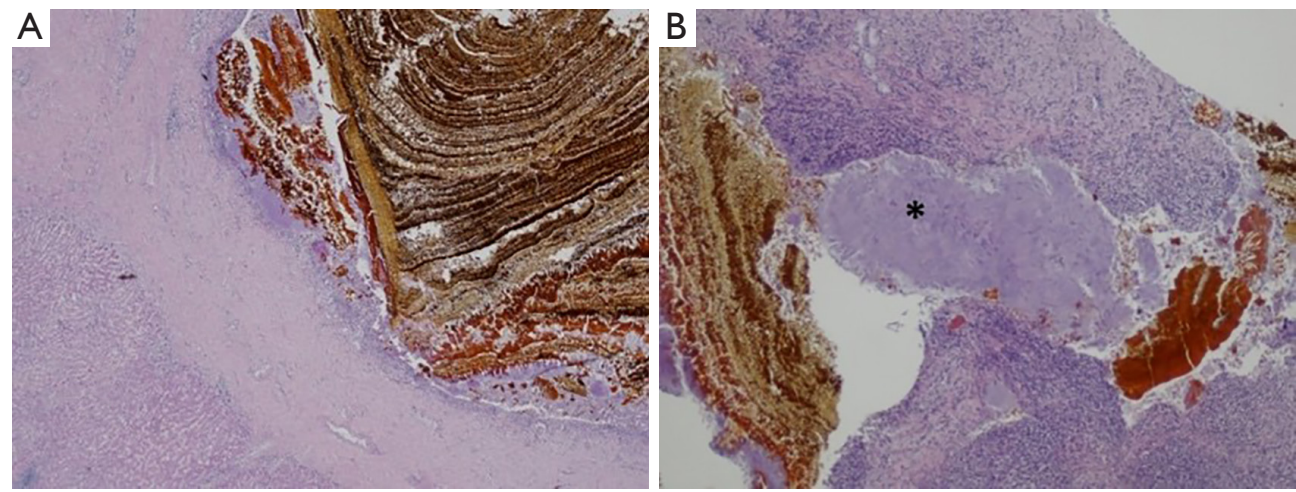

Figure 5 Intrahepatic lithiasis. (A) The lithiasis material is observed dilating the intrahepatic bile duct, hematoxylin-eosin, 40x; (B) and associated with chronic inflammation and presence of actinomyces $\left(^{*}\right)$, hematoxylin-eosin, $40 \times$.
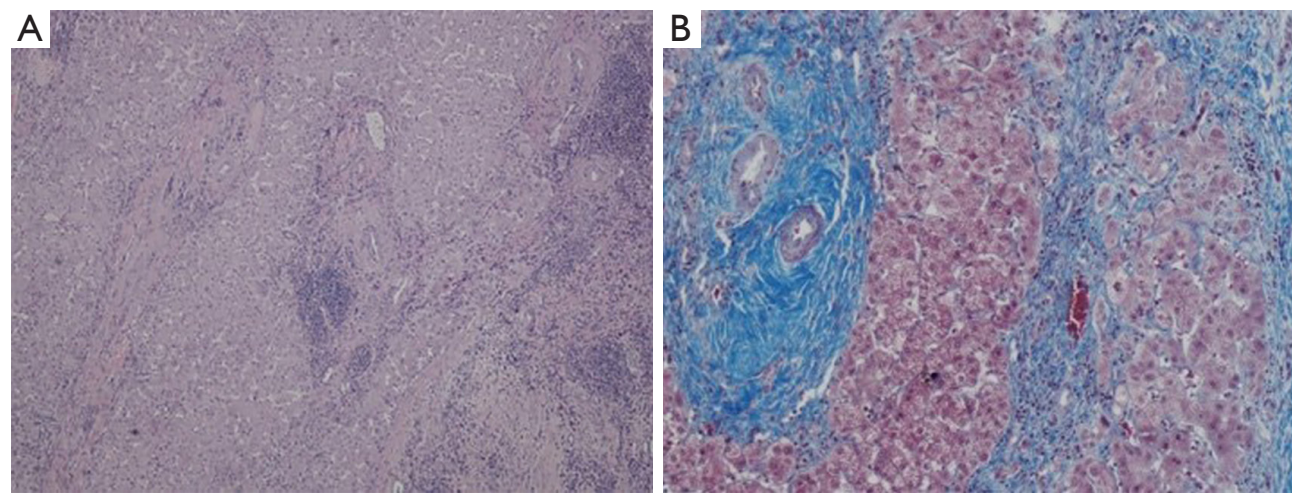

Figure 6 Portal and lobular inflammation. (A) With prominent portal fibrosis, formation of fibrous bridges, hematoxylin-eosin, 40x; (B) and parenchymal nodules in Masson's trichrome stain, Masson's trichrome, 100x.

There are more than ten different species, forming part of the commensal bacterial flora of the aerodigestive tract and female reproductive tract. Six of these are associated with human disease, frequently Actinomyces israelii (3).

The main risk factors associated with actinomycosis are loss of integrity of the gastrointestinal tract mucosa, previous abdominal surgery, intra-abdominal infection, presence of gastrointestinal foreign body and immunosuppression (4).

One study reported association in $17.5 \%$ of cases with a history of abdominal or pelvic procedure performed in the last year and the development of abdominal actinomycosis (5). The cases of hepatic actinomycosis have been reported in the literature as secondary to intra-abdominal or thoracic infection, with the bacilli reaching the liver through direct extension or via the portal vein. The arrival of bacilli via the portal frequently has a cecal or appendicular infectious origin. Occasionally there is evidence of a hepatic lesion that presents clinically as a hepatic abscess (6).

The infection is generally chronic, producing a fibrous organization that can frequently appear as a tumor-like mass (7).

Generally actinomyces infections are cryptogenic in nature $(80 \%$ of the cases) $(8,9)$. There are two reports of actinomyces associated with biliary or pancreatic infection (10). In one report the infection is associated with gall stones that accidentally fell into the abdominal cavity, and in the other it was due to the use of a pancreatic prosthesis. In our case the $\mathrm{T}$ tube fragment could have acted as a foreign body and facilitated the infection by actinomyces.

The treatment of main bile duct lithiasis has evolved from open therapy with the use of a T-tube to laparoendoscopic therapy, with T-tube therapy being an increasingly less used practice. The use of the $T$ tube is associated with complications such as biliary fistula, biliary peritonitis upon removal, hydroelectrolytic imbalance and, as in this case, break-up on removal with a fragment 
remaining in the bile duct.

The finding that was interpreted initially as a stenosis using NMR, with the corresponding suggestion of cholangiocarcinoma as a differential diagnosis, was a fragment of an old $\mathrm{T}$ tube.

In patients who present recurrent lithiasis of the main bile duct, it is important to conduct imaging studies of the bile duct to discard hepatolithiasis or Caroli's disease, where magnetic resonance is the most complete non-invasive imaging study. The episodes of recurrent cholangitis that do not receive suitable treatment can cause biliary cirrhosis, as the biopsy in this case showed.

\section{Acknowledgments}

Funding: None.

\section{Footnote}

Reporting Checklist: The authors have completed the CARE reporting checklist. Available at https://asj.amegroups.com/ article/view/10.21037/asj-19-3/rc

Peer Review File: Available at https://asj.amegroups.com/ article/view/10.21037/asj-19-3/prf

Conflicts of Interest: All authors have completed the ICMJE uniform disclosure form (available at https://asj.amegroups. com/article/view/10.21037/asj-19-3/coif). The authors have no conflicts of interest to declare.

Ethical Statement: The authors are accountable for all aspects of the work in ensuring that questions related to the accuracy or integrity of any part of the work are appropriately investigated and resolved. All procedures performed in this study were in accordance with the ethical standards of the institutional and/or national research committee(s) and with the Helsinki Declaration (as revised in 2013). Written informed consent was obtained from the patient for publication of this case report and accompanying images. A copy of the written consent is available for review by the editorial office of this journal.

Open Access Statement: This is an Open Access article distributed in accordance with the Creative Commons Attribution-NonCommercial-NoDerivs 4.0 International
License (CC BY-NC-ND 4.0), which permits the noncommercial replication and distribution of the article with the strict proviso that no changes or edits are made and the original work is properly cited (including links to both the formal publication through the relevant DOI and the license). See: https://creativecommons.org/licenses/by-nc-nd/4.0/.

\section{References}

1. Wills VL, Gibson K, Karihaloot C, et al. Complications of biliary T-tubes after choledochotomy. ANZ J Surg 2002;72:177-80.

2. Santos-Rosa OM, Lunardelli HS, Ribeiro-Junior MA. Pyogenic liver abscess: diagnostic and therapeutic management. Arq Bras Cir Dig 2016;29:194-7.

3. Brook I. Actinomycosis: diagnosis and management. South Med J 2008;101:1019-23.

4. Chen LW, Chang LC, Shie SS, et al. Solitary actinomycotic abscesses of liver: report of two cases. Int J Clin Pract 2006;60:104-7.

5. Sharma M, Briski LE, Khatib R. Hepatic actinomycosis: an overview of salient features and outcome of therapy. Scand J Infect Dis 2002;34:386-91.

6. Burt A, Ferrell L, Hubscher S, et al. MacSween's Pathology of the Liver. 6th ed. Philadelphia: Elsevier, 2011.

7. Manucha V, Haluszka O. Pancreatic actinomycosis: possible complication of long-term pancreatic stenting, diagnosed on endoscopic retrograde cholangiopancreatography guided pancreatic duct brushings. Journal of Digestive Endoscopy 2014;5:154-6.

8. Tiftikci A, Vardareli EN, Kaban K, et al. Actinomycotic hepatic abscess. Hepatol Int 2008;2:133-5.

9. Ávila F, Santos V, Massinha $\mathrm{P}$, et al. Hepatic actinomycosis. GE Port J Gastroenterol 2015;22:19-23.

10. Ramia JM, Mansilla A, Villar J, et al. Retroperitoneal actinomycosis due to dropped gallstones. Surg Endosc 2004;18:345-9.

doi: $10.21037 /$ asj-19-3

Cite this article as: Losada $\mathrm{HF}$, Troncoso AI, Herrera HA, Silva JA, Alvarado JA, San Martín PI, Becker RE. Kehr tube complication: recurrent hepatic abscess associated with actinomyces secondary to a foreign body in the bile duct-a case report. AME Surg J 2021;1:20. 